\title{
DESIGN AND DATA INTEGRATION IN MIXED METHODS \\ RESEARCH: CHALLENGES AND WAYS FORWARD
}

Rai, Krishna Bahadur ${ }^{9}$

\begin{abstract}
Mixed Methods Research (MMR) has been taken as a latest and more practical approach in the field of social science. It has the opportunity of mixing the strengths of both Quantitative (QUAN) and Qualitative (QUAL) methods but has also the challenges of mixing these strengths into the process. The practitioners have been facing the challenge of integrating the design, data sampling, collection, analysis and collection of findings. However, the scholars have proposed multiple ways of conducting the research and coming out from the potential challenges. It explores the conceptual frame and methodological procedures for conducting MMR in the research studies so that the challenges would be illuminated as much as possible. For using any of those typologies, some properties like open-mindedness, aware of methodological corruption and accountable to the stakeholders are essential for a researcher.
\end{abstract}

Keywords: Mixed Methods Research, Paradigm, Pragmatism, Quantitative, Qualitative

\section{Background}

In recent years, Mixed Methods Research (MMR) has been considered as a legitimate and stand-alone approach which is popular among the researchers who have not stood within the boundaries of only quantitative (QUAN) or qualitative (QUAL) approach. The MMR has been taken as a midway between the extremes of Plato (quantitative approach) and the Sophists (qualitative approach), and scholars have been attempting to enjoy respectfully the wisdom of both of these worldviews while also seeking a workable middle solution for the research problems (Johnson, Onwuegbuzie \& Turner, 2007). The central premise of MMR is jointly used of QUAN and QUAL approaches in a research project which provides a better understanding of research problems and complex phenomena than either approach alone (Molina Azorin \& Cameron, 2010). It has been taking as another level of synthesis employing both ideas of QUAN and QUAL research.

9 Mr. Rai is associated with Kathmandu University, School of Education, Hattiban, Lalitpur, Nepal. Email: kraimrg@gmail.com 
Being the third and latest alternative in the research field, MMR is not debate-free and "the fundamental issue of the degree to which mixed methods researchers genuinely integrate their findings has not been addressed to a significant extent" (Bryman, 2007). MMR obviously attempts to mix the divergent paradigms across the ontological stage to methodological processes with maintaining the internal integrations which have been feeling more complex and the scholars have been placing the polarized logics and creating debates on its definition, methods and quality. During the process of real integration of QUAN and QUAL approaches in a particular study, the practitioners have been feeling as a more complex journey than falling into a particular category of research approach (Maxwell \& Loomis, 2003). The integration of design and data are some strategic in holistic due to the nature of data and its destination of reality. How to harmonize the data from both methods? Here might be some confusions and will not be debate-free from other scholars. Therefore, it obviously has the challenges during the process of mixing.

\section{Objectives}

The objective of the study is

- To review the challenges of methodological integration when using MMR.

- To explore the conceptual frame and methodological procedures in conducting MMR.

\section{Methodology}

The study is the methodological review of the Mixed method and reviewed challenges in the procedure of these researches.

Features of QUAN and QUAL

The QUAN believes to logical-positivism and post-positivism, and the QUAL to several epistemologies and metatheories, such as interpretivism, hermeneutics, or constructivism (Fidel, 2008). QUAN approach investigates a single "truth" objectively verifiable and independent. It believes to the replicability, and generalizability of findings, and interested to future predictions. This approach assumes to the statistical hypothesis demanded by the research questions and uses the instruments like tests or surveys to collect data and reliance on probability theory. It claims the strengths of accurate operationalization and 
measurement of a specific construct. It conducts group comparisons; checks the strengths of associations between variables of interest and specifies the model through testing of research hypothesis (Castro, Kellison, Boyd \& Kopak, 2010). The research results are relatively independent e.g. effective size, statistically significance, less time consuming and produces higher credibility with many people in power i.e. administrators, politicians, people who fund programs (Johnson \& Onwuegbuzie, 2004).

On the other side, QUAL examines the things in the natural settings, make sense of, or interpret, phenomena for making the meanings of the particular settings. Qualitative data are in-depth descriptions of circumstances, people, interactions, observed behaviors, events, attitudes, thoughts and beliefs, and direct quotes from people who have experienced or are experiencing the phenomenon (Patton, 2002). The QUAL has the strengths of generating rich and detailed understandings of human experiences, emotions, beliefs, behaviors depending on the original contexts. Moreover, it attains an in-depth analysis of complex human, family systems, and cultural experiences. Therefore, QUAL approaches response to the social conditions, local settings and the needs of the stakeholders.

Both research approaches have also their limitations from ontological stands to methodologies. QUAN invites the detachment from its 'real world' context and refers to as decontextualization of the research process. The QUAN researchers engage in testing the phenomena through theory and hypothesis rather than producing new theories. It produces too abstract and general knowledge and might get complication during the direct application to specific local situations, contexts, and individuals (Johnson \& Onwuegbuzie, 2004).

On the other hand, the QUAL deals with very small and purposive sample which is unrepresentative of the population. The researcher's personal biases and idiosyncrasies can easily influence the results (Johnson \& Onwuegbuzie, 2004). The crises of representation, legitimation and praxis exist in the qualitative paradigm and more of the practitioners are hanging on these hooks during their research endeavors. This approach believes that the knowledge is the products of cultural and personal constructs which is partial and not enough. Therefore, the QUAL has not the capacity for producing generalizable findings and the qualitative scholars have accepted that the jargons of a quantitative approach like generalizability, replicability, reliability and validity are not relevant for this approach. 
Majorly, the QUAN and QUAL are in the practice from the very beginning in the social science research and raising opposite logic to each other. The researchers have been experiencing the dilemma during their venture to reach to the reality of the world. The purists of both approaches are advocating their own traditions and the debates are against the solution of these issues of ontological differences. Recently, MMR has emerged with the promise of bridging across both traditions. The scholars of MMR have perceived as incomplete to follow either QUAN or QUAL approach during the journey of research. Thus, it has been established as a distinct approach in the social and behavioral sciences for more than three decades, which combines both forms of data and considers to the analysis of problems beyond simple numbers in a quantitative sense or words in a qualitative sense (Creswell \& Plano Clark, 2011). However, the MMR has the issues of genuine integration of both QUAN and QUAL approaches.

A series of principles describe how integration occurs at the levels of study design, method, interpretation and reporting. The qualitative data can be used to assess the validity of quantitative findings. Quantitative data can also be used to help generate the qualitative sample or explain findings from the qualitative data (Fetters, Curry \& Creswell, 2013). It is easy to say both of the approaches are mutually supportive to validate or go deep down to the research works. But, the work of integration is not easier to deal with the data collected by these divergent epistemic ways.

\section{Discussion/Analysis}

Integration and Its Rationale

The mixed model comprises the different approaches at any or all of a number of stages through the research. MMR mixes or combines QUAN and QUAL research approaches and includes the techniques, methods or language into a single study. It is more labor-intensive than the single paradigm; therefore, the researcher must be known to both traditions. MMR refers to an emergent methodology that advances the systematic integration, or 'mixing', of QUAN and QUAL data within a single investigation or sustained program of inquiry. The 'mixing' may be nothing more than a side by side or sequential use of different methods, or it may be that different methods are being fully integrated into a single analysis. But, other scholars have introduced majorly two types of mixing i.e. sequential and parallel. Under these approaches, they have disaggregated into many types 
and ways of integration so that the researchers enjoy the most freedom to their works.

Some of the scholars have given high sounding importance to MMR and said, the integration of QUAN and QUAL data can dramatically enhance the value of research findings. Moreover, using multiple methods increases the robustness of results because findings can be strengthened through triangulation and cross-validation. The robust results can provide the knowledge close to the human practices so that contribute more to the human society. They have motivated to mix these methods in a study that the quality of a research work can be improved when the biases, limitations, and weaknesses of a method following one approach are counterbalanced, or compensated for, by mixing with a method belonging to the other approach (Fidel, 2008). A researcher can use the strengths of an additional method to overcome the weaknesses in another method by using both in a research study. Moreover, it is an attempt to legitimate the use of multiple approaches in answering research questions, rather than restricting or constraining researchers' choices and rejects dogmatism (Johnson \& Onwuegbuzie, 2004).

Obviously, MMR accumulates the strengths of both QUAN and QUAL approaches by mixing the methods which produce more practical findings and also minimizes the limitations arising to the individual approach. Using MMR allows researchers to address the issues more widely and completely than one method could, which in turn amplifies the richness and complexity of the research findings (Fidel, 2008). It has evolved to the point where it is "increasingly articulated, attached to research practice, and recognized as the third research approach or research paradigm" (Johnson, Onwuegbuzie, \& Turner, 2007; Denscombe, 2008). Methodological pluralism is a key feature of MMR, which search the results in broader than those offered by mono method designs. It combines the strengths of both approaches and enjoys to the rigorous analysis of data which meet the reliability and validity. Many of the research practitioners as above have stated the benefits of MMR for producing more purified findings and practical conclusions.

Key Challenges of Integration

The scholars of MMR have been experiencing some challenges on originating the design and process integration when have to choose this to their research study. Mixing the design and data of QUAN and QUAL to consolidate the value commitments is highvalued as well as problematic. During a research project, the value commitments might 
be the same or different from the collected data through QUAN and QUAL approaches. It is a process of integrating the ontological and epistemic stands of both approaches for producing the more credible results with the data received from the respondents/ participants is a major challenge in MMR. The experiences showed the difficulty to a single researcher to carry out both QUAN and QUAL research concurrently and referred by Johnson and Onwuegbuzie (2004) to a team approach. Highly experienced researchers may conclude the realistic results which might not be practical to others.

At the Paradigm Level

In particular, treating realism and constructivism as paradigms, points to broad differences in social scientists' assumptions about the nature of knowledge and the appropriate ways of producing such knowledge (Guba \& Lincoln, 2005). Making the connection between paradigms and issues surrounding to combining of qualitative and quantitative methods, indicates to the many factors that go into decisions about what to study and how to do such a study (Morgan, 2007). It is a third way of combining the single truth-which is tangible and fragmentable and multiple realities - due to the fact of pluralization of lifeworlds. The pragmatic researchers are armed with a bi-focal lens (i.e. both QUAN and QUAL), rather than a single lens and they are able to zoom in to microscopic detail or to zoom out to indefinite scope (Onwuegbuzie \& Leech, 2005). They have accepted to integrate both QUAN and QUAL approaches in one research project as the bi-focal lens. But, there are greater complexity and diversity in thinking and mounting various confusions from starting to ending of the study.

These two QUAN and QUAL camps have involved the positivists on one side and interpretivism on the other side and resulted in two research subcultures, one professing the superiority of 'deep and rich observational data' and the other the virtues of 'hard and generalizable' survey data. The purists have argued that combining QUAN and QUAL is impossible because of the paradigmatic contradictions, because these two different methods reflect different epistemologies. This issue has been referred to as the 'paradigm debate'. From this perspective, MMR is viewed as untenable i.e., incommensurable or incompatible because certain paradigms and methods could not 'fit' together legitimately (Smith, 1983). Their major argument is "It is not possible to combine, merge, or reconcile a view of reality as singular and objective (positivist) with views of it as multiple and 
individually or culturally constructed (constructivist), or as historically contingent (critical theory)" (Sandelowski, 2000, p. 247). The purists of both camps have been placing the logic of incompatibility of paradigmatic thoughts; thus, they have claimed the impossibility of combining these approaches in a single study.

At the Method Level

Combinations at the method level can be used to expand the scope of a study to capture method-linked dimensions of a targeted phenomenon. Today, the researchers are increasingly trying to be more interdisciplinary, rigorous and dynamic; therefore, they need to harmonize one method with another, and the researchers need a comprehensive understanding of multiple methods (Johnson \& Onwuegbuzie, 2004). MMR combines both nomothetic and idiographic approaches in an attempt to serve the dual purposes of generalization and in-depth understanding to gain an overview of social realities from a larger sample while understanding the other through a detailed study of a smaller sample (Bazeley, 2004).

When we examine singly, QUAN approach is based on the model of controlling the variables and testing pre-specified hypotheses. This approach focuses on deduction, confirmation, theory/hypothesis testing, explanation, prediction, standardized data collection, controlled experiments and statistical analysis (Johnson \& Onwuegbuzie, 2004). In contrast, QUAL approach focuses on induction, discovery, exploration, theory/ hypothesis generation, the researcher as the primary "instrument" of data collection, and qualitative analysis (Johnson \& Onwuegbuzie, 2004). Thus, the QUAL methods are based on the detailed observation of the 'researched' with prolonged involvement in the given natural settings without pre-assumptions.

When these methods are integrated without careful consideration of the particular assumptions or rules and expectations regarding their conduct, corruption of those methods can occur such that results obtained by them become subject to question (Bazeley, 2004). For making more credible results by integrating both methods are one of the major challenges in the venture of MMR. The portion of the corruption of methods would be higher and the situation would be out of the discipline as expected and the researchers might be blamed in the field of their accountability towards the stakeholders. Therefore, the 
methodological blending is a level of bearing the multiple inconsistencies and confusions to the researcher/s to make the smooth flow of both deduction and induction processes.

\section{At Technique Level}

In MMR, the researcher collects data from both QUAN and QUAL strategies, approaches, and methods in such a way that the resulting mixture or combination is likely to result in complementary strengths and non-overlapping weaknesses. The data collected from two methods designate to opposite poles and the researcher feels the challenge to combine the findings in spite of getting the conducive condition. It is not easy to mix like water and sugar as the scholars have visualized the way of finding the knowledge of 'what works'. How do you mix to the piece of stone with water? The researcher may perceive as an extra burden and drag the unnecessary tensions. The utilization of the techniques of both approaches might be felt in the process of making more complex knowledge manufacturing to the novice researchers.

Greene et al., (1989) have recommended three purposes of mixing at technique level which include triangulation, complementarity and development. Triangulation helps to achieve or ensure corroboration of data, or convergent validation. Testing from the different instrument and measuring tapes on looking the corroboration of data and validation findings is sincerer and some hazardous work for all of the researchers. But, it is not possible and necessary to triangulate to all of the social issues in reality. Complementarity promotes to clarify, explain, or otherwise more fully elaborate the results of analyses. The results from two methodologies may contradict each other and the researcher may be filled with confusions. The third purpose is a development which indicates the use of additional sampling, data collection and analysis techniques; the researcher might feel additional burden due to the limited time and money. At the technique level, I have collected the challenges of doing a qualified MMR in the following stages and collected some findings.

Issues of Sample Size and Approach

MMR follows the process of mixing of highly structured instruments for data collection with much less structured ones (Fidel, 2008). The declaration of sample size for MMR is one of the challenging parts in the research process. Which sample size is appropriate for 
collecting both data QUAL and QUAN? Is it possible to confirm a size of the sample for collecting data through both approaches? QUAL approach involves purposeful sampling to enhance understanding of the information-rich case which is oriented toward the development of idiographic knowledge from individual cases. One pervasive qualitative practice in sample selection is the goal of 'reaching saturation'. Saturation promotes to the 'just enough' sized samples which are not acceptable by the quantitative approach for generating credible research results. For example, symbolic interactionists argue that every case is a sample of its broader population, that similarities across a population are greater than differences between populations, and therefore that it is appropriate to treat each case as being, in general terms, representative of their population. These approaches are unacceptable, however, to statisticians (Bazeley, 2004).

On the other hand, to be precise, inferential statistics, which is used to analyze quantitative data, are based on the assumptions of a random selection of samples, and error rates are proportional to sample size. Therefore, QUAN approach ideally involves probability sampling to permit statistical inferences to be made which is oriented toward the development of nomothetic knowledge, from samples to populations (Sandelowski, 2000). MMR in the stage of taking sample size has a serious dilemma which will be widely accepted by the research scholars and zero-issue level.

\section{Data Collection Procedure}

There are majorly five types of data collection methods used in the field of social science research: surveys, semi-structured/unstructured interviews, focused group discussion, observations, and historical/archival research (Axinn \& Pearce, 2006). The QUAN researchers use the structured questionnaires for seeking 'more objective' measures to evaluate the validity of 'more subjective' measures. In contrast, the QUAL researchers use open-ended and unstructured interviews for capturing the subjective findings taking particular cases.

For integrating the aspects of both methods, MMR has been following two approaches of data collection i.e. concurrent and sequential. Concurrent strategies have been employed to validate one form of data with the other form, to transform the data for comparison, or to address different types of questions (Creswell \& Plano Clark 2011). Sequential involves collecting data in an iterative process whereby the data collected in one phase 
contribute to the data collected in the next (Driscoll et al., 2007). Either Concurrent or

Sequential, the data collection processes are different from each other. It is not possible and practiced to collect the data in a same form and checklist. Thus, the researchers collect data separately but the issue is the same and not possible to mix the data collection process.

\section{Data Analysis}

To construct a mixed-method design, the researcher must make two primary decisions: (a) whether one wants to operate largely within one dominant paradigm or not, and (b) whether one wants to conduct the phases concurrently or sequentially (Burke Johnson \& Onwuegbuzie, 2004). The collection and analysis of both QUAN and QUAL data in a single study in which the data are collected concurrently or sequentially, are given a priority, and involve the integration of the data at one or more stages in the process of research.

MMR uses the logic of inquiry which includes the use of induction - the discovery of patterns, deduction - testing of theories and hypotheses, and abduction - uncovering and relying on the best of a set of explanations for understanding one's results (Burke Johnson \& Onwuegbuzie, 2004). But, QUAN generally depends on scientific assessments objectivity and have multiple ways of presenting the data like; table, figures where QUAL follows the interpretive information collected from the experienced. Therefore, the researchers get difficulty to combine during analysis and interpretation.

It is the stage where the results obtained from data collected, Concurrently or Sequentially can be mixed and the third findings will be produced. Today researchers have developed more complex designs, combined more diverse kinds of data, and integrated different types of data into their analyses more carefully than in the past. During the analysis and integration of both results, there might be the same findings with some contradictions. When a researcher finds the contradictions, s/he would bear some process-tension and verify or returned back to dig out the causes. The final finding will be there where the researcher is satisfied with his/her data and analysis with validation where the challenge of finding the point or level of satisfaction is. But, it is not sure that all of the stakeholders will be completely satisfied due to the chances of incompatible mixing during the analysis and concluding the finding. The findings might only make satisfied to the researcher who 
involved but the stakeholders might find the multifaceted findings and get complication on their utilization in the real field.

Ways to Address the Challenges

The paradigmatic issues raised in MMR remain unresolved. Indeed, one could not prove that the paradigmatic debates can never be resolved (Bazeley, 2004). Being such situation, the scholars of MMR have been advocating that the quantitative procedures are not always objective, and qualitative procedures are not always subjective (Hanson et al., 2004). They argued that the MMR may be used to combine the representativeness and generalizability of quantitative findings and the in-depth, contextual nature of qualitative findings. The literature has been recommended to MMR as the latest approach with the challenges in multiple stages but not impossible to address those challenges. The following strategies help us to conduct MMR with the situation of tensions minimized.

Paradigmatic Clarity

Pragmatism is a paradigm which invites to MMR to produce the more practical knowledge for human society (Johnson \& Onwuegbuzie, 2004). It draws on many ideas including using 'what works', using diverse approaches, and valuing both objective and subjective knowledge. The pragmatists advocate for collecting the practical findings of all research works and refer to integrate those QUAN and QUAL methods within a single study. Indeed, pragmatists ascribe to the philosophy that the research question should drive the method(s) used, believing that 'epistemological purity doesn't get research done' (Onwuegbuzie \& Leech, 2005). The pragmatism invites to both QUAN and QUAL in a single bowl to combine the methods and processes for producing more practical findings with new and unique taste to the social world; hence, it is a fusion-point of paradigm debates and provides a clear highway of combining design and data within the MMR.

An open-minded researcher is appropriate for utilizing the beauties of MMR. The dialectical mixed methods researcher embraces each of the incompatible paradigms, and carefully navigates between them when working in the QUAN versus QUAL domains (Fila, Hess \& Purzer, 2015). It is possible to integrate quantitative and qualitative methods, combining these methods introduces both testability and context into the research. MMR is highly appreciated as an approach of using divergent methods which covers the wider 
range of data collection and analysis that ensures the result in the fuller picture than from the study using a single approach.

\section{Alternative Design Typologies}

For making more credible and well-designated to the researchers, Greene and Caracelli (1997) have introduced a typology frame taking two categories or alternative designs i.e. component and integrated. 'Component' designs include three alternative ways of producing the more comprehensive results/conclusions like triangulation, complementarity and expansion. 'Triangulation' corroborates the findings from different methods where 'complementarity' takes one dominant method and elaborates through the findings of another method. The third, 'expansion' follows the different methods and presents the results side by side. The 'component design' does not mix the data collected in the analysis stage but interprets jointly to the findings from different methods.

On the other hand, integrated design disaggregates to four specific ways i.e. iterative, embedded or nested, holistic and transformative. 'Iterative design' explores the dynamic interplay of findings from different methods throughout the evaluation. The second, 'embedded or nested' locates one method into another and plays into "creative tension". Nesting refers to the extent to which multiple data types are collected from the same actors, organizations, or entities (Small, 2011). This design integrates the data for taking one major and another supportive to conclude findings. The creative tension might be there the supportive method may lead to the main method in findings. The third, 'holistic' integrates the methods throughout the study for building one integrated explanation of results. The fourth, 'transformative' mixes methods to capture different value commitments which can lead to "reconfiguring the dialog across ideological differences" (Greene \& Caracelli, 1997, p. 24).

Creswell \& Plano Clark (2007) have also introduced a constructive typology with multiple alternatives in design. They have given four major design types i.e. triangulation, embedded, explanatory and exploratory. The triangulation design follows the concurrent approach which is "characterized by the collection of both types of data during the same stage" (Castro et al., 2010, p. 344). The embedded design follows either concurrent or sequential approach accepting as a larger design to QUAN or QUAL. In sequential designs, either the qualitative or quantitative data are collected in an initial stage, followed 
by the collection of the other data type during a second stage.

Table no. 1: Typology of MM Design and Variants

\begin{tabular}{|c|c|c|c|}
\hline Design Type & Timing & Mix & Weighting/Notation \\
\hline Triangulation & $\begin{array}{l}\mathrm{C} \text { o } \mathrm{n} \mathrm{c} \text { u r } \mathrm{rent} \text { : } \\
\text { quantitative and } \\
\text { qualitative at the same } \\
\text { time }\end{array}$ & $\begin{array}{l}\text { Merge the data during } \\
\text { interpretation or analysis }\end{array}$ & QUAN + QUAL \\
\hline Embedded & $\begin{array}{ll}\text { Concurrent and } \\
\text { sequential }\end{array}$ & $\begin{array}{l}\text { Embed one type of data } \\
\text { within a larger design } \\
\text { using the other type of } \\
\text { data }\end{array}$ & $\begin{array}{l}\text { QUAN (qual) Or } \\
\text { QUAL (Quan) }\end{array}$ \\
\hline Explanatory & $\begin{array}{l}\text { S e q u e } n \text { t i a } 1 \text { : } \\
\text { Quantitative followed } \\
\text { by qualitative }\end{array}$ & $\begin{array}{l}\text { Connect the data } \\
\text { between the two phases }\end{array}$ & QUAN \\
\hline Exploratory & $\begin{array}{l}\text { Sequential: Qualitative } \\
\text { followed by } \\
\text { quantitative }\end{array}$ & $\begin{array}{l}\text { Connect the data } \\
\text { between the two phases }\end{array}$ & $\begin{array}{l}\text { QUAL } \\
\text { QUA }\end{array}$ \\
\hline
\end{tabular}

(Creswell \& Clark, 2007)

The triangulation design is defined as the concurrent from the beginning to ending and the embedded design might be either concurrent or sequential and one will be dominant both QUAN and QUAL. Explanatory leads by QUAN and exploratory leads by QUAL (Creswell \& Plano Clark, 2007). Through, either sequential or concurrent, MMR integrates the methodology and data in a research work. "Even among mixed methods studies, a common limitation has been the use of qualitative and quantitative approaches in a sequential temporal order, thus limiting the integration of both data forms under a unified process of data analysis" (Bryman, 2007).

Likewise, Fetters, Curry and Creswell (2013) have also acknowledged three basic designs of integration which includes (1) exploratory sequential; (2) explanatory sequential; and (3) convergent designs. In sequential designs, the intent is to have one phase of the mixed methods study build on the other, whereas in the convergent designs the intent is to merge 
the phases in order that the quantitative and qualitative results can be compared.

Clarity in Methods and Techniques

Taking a non-purist or compatibilist or mixed position allows researchers to mix and match design components that offer the best chance of answering their specific research questions (Johnson \& Onwuegbuzie, 2004). The data collection and analysis techniques are not linked to paradigms. Both QUAN and QUAL researchers may use interviews and even the very same standardized measures to answer their questions, but they will employ these techniques and, more importantly, analytically treat their results differently (Sandelowski, 2000).

Creswell and Plano Clark conceptualize integration to occur by linking the methods of data collection and analysis (Creswell et al. 2011). Fetters, Curry and Creswell (2013) have introduced several ways of integration (Table 2) i.e. connecting, building, merging and embedding (p. 6).

\section{Table 2: Integration through Methods}

\begin{tabular}{|l|l|}
\hline Approach & Description \\
\hline Connecting & One database links to the other through sampling \\
\hline Building & One database informs the data collection approach of the other \\
\hline Merging & The two databases are brought together for analysis \\
\hline Embedding & Data collection and analysis link at multiple points \\
\hline
\end{tabular}

(Fetters, Curry \& Creswell, 2013)

With debate on the value of QUAN versus QUAL moderating to a recognition that both have a place, the 'real issues', according to Patton (1989), have become 'methodological flexibility and appropriateness' (Bazeley, 2002, p. 144). The technique-level-integration involve the sampling, data collection, and data analysis techniques commonly (although not necessarily) conceived as QUAN or QUAL; because the techniques are tied neither to paradigms nor to methods and combinations at the technique level permit innovative uses of a range of techniques for a variety of purposes (Sandelowski, 2000). The MMR scholars have advocated its possibility and practicing to the integration at technique level but differently. The major conception of integration is at technique level majorly during sampling, data collection and analysis stages. 
In the technique level, combining sampling strategies is one of the major parts for adequate integration of data in a research study. Sandelowski (2000) has recommended to purposeful and probability sampling for integrating usefully. To increase representation, Onwuegbuzie and Leech (2007) have introduced the power analyses in MMR. Such power analyses provide researchers with information regarding appropriate sample sizes for both QUAN and QUAL phases of a mixed methods investigation. For example, Bazeley (2002) has stated that where the total $N$ is less than 20, it is inappropriate to report percentages, and few inferential statistical procedures can be applied to such small samples. The chisquare statistic neither is validly used to test a relationship between variables where there are small expected frequencies nor where categories are not mutually exclusive; and samples in the range of 10 to 20 cases per variable are required for multivariate analyses. The opportunity for detailed study while maintaining balance and variety may be more important than satisfying selection criteria based on a sampling of attributes.

Likewise, data collection and analysis are also the important stages of integration in MMR. The design typologies have given numbers of alternatives for collecting and integrating the data in the major forms of concurrent and sequential. The data collection techniques can be selected which the researcher takes as appropriate from the techniques used by QUAN and QUAL approaches. Regarding the data analysis, Onwuegbuzie and Teddlie (2003) have given seven- stage conceptualization of the mixed methods data analysis process i.e. data reduction, data display, transformation, correlation, consolidation, comparison and integration. The process provides a better runway for analyzing the data during a research project through MMR.

\section{Conclusion}

Paradigmatically, the researcher has a challenge of staying in 'the middle of a road' when s/he accepts to Pragmatism and employ MMR to his/her research work. S/he would ensure justice equally to 'deep and rich observational data' and 'hard and generalizable survey data'. There are multiple challenges of articulating a balanced situation between the induction and deduction process during data collection and analysis which are guided by polarized philosophical strands. There might be a chance of methodological corruption due to the lack of careful consideration and scholastic preparedness. During the analysis phase, establishing the connections, building the ligaments, merging, embedding and 
contrasting are the major challenging areas where the researchers' courage will be reflected.

This is only a process of creative tensions and not impossible to travel to the multilayer analysis that devoted to 'what works'; the researcher should be an open-minded. Paradigmatically, the pragmatism and transformative approaches invite to the mixing the QUAN and QUAL. There are numbers of design alternatives accepted and have the permission of using a range of techniques innovatively during technique level integration. Complementarity and triangulation are possible in MMR which can produce the comprehensive results. Hence, MMR contributes to make a research more fruitful and produces the more purified findings. Both concurrent and sequential data collecting and analysis provide the highway of an integrated approach. The process of connecting the data, building best data collection and mixture, merging both data and, embedding the data collecting and analysis are the major recommended procedures for data integration. During the sampling, no one has researched and proved that the sample size should be the same and the parameters of analysis in a controlled mentality. The methodological blending is possible only at the stage of analysis and findings collection.

\section{References}

Axinn, W. \& Pearce, L. D. (2006). Mixed method data collection strategies. New York: Cambridge.

Bazeley, P. (2004). Issues in mixing qualitative and quantitative approaches to research. In R. Buber, J. Gardner, \& L. Richards (eds), Applying qualitative methods to marketing management research (pp. 141 - 156). UK: Palgrave Macmillan.

Bruke Johnson, R. \& Onwuegbuzie, A. J. (2004). Mixed methods research: A research paradigm whose time has come. Educational Researcher, 33(7), 14-26.

Bryman, A. (2007). Barriers to integrating quantitative and qualitative research. Journal Mixed Methods Research, 1, 8 -22. doi: 10.1177/2345678906290531.

Creswell, J. W., Plano Clark, V. L., Gutmann, M. L., \& Hanson, W. E. (2003). Advanced mixed methods research designs. In A. Tashakkori \& C. Teddlie (Eds.), Handbook of mixed methods in social and behavioral research (pp. 209-240). Thousand 
Oaks, CA: Sage.

Creswell, J. W. \& Plano Clark, V. (2011). Designing and conducting mixed methods research. Thousand Oaks: Sage.

Denscombe, M. (2008). Communities of practice: A research paradigm for the mixed methods approach. Journal of Mixed Method Research, 2(3), 270 - 283, doi: $10.1177 / 1558689808316807$.

Denzin, N. K., \& Lincoln, Y. S. (2005). Introduction. In N. K. Denzin \& Y. S. Lincoln (Eds.), The SAGE handbook of qualitative research (3rd ed., pp. 1-29). Thousand Oaks, CA: Sage.

Driscoll, D. L., Appiah-Yeboah, A., Salib, P. \& Rupert, D. J., (2007). Merging qualitative and quantitative data in Mixed Methods Research: How to and why not. Ecological and Environmental Anthropology, 3 (1), 18 - 28.

Fetter, M. D., Curry, L. A. \& Creswell, J. W. (2013). Achieving integration in Mixed Methods Designs - principles and practices. Health Research and Educational Trust, 48 (6/2), 2134 - 2156, doi: 10.1111/1475-6773.12117.

Fidel, R. (2008). Are we there yet? Mixed methods research in library and information science. Library \& Information Science Research 30, 265 - 272, doi: 10.1016/j. lisr.2008.04.001.

Fila, N. D., Hess, J. L. \& Purzer, S. (2015). A dialectic data integration approach for mixed methods survey validation. 122th ASEE Annual Conference and Exposition (14 - 17 June), American Society for Engineering Education, Seattle, W. A.

Flick, U. (2010). An introduction to qualitative research. New Delhi: Sage.

Greene, J. C., \& Caracelli, V. J. (1997). Advances in mixed-method evaluation: The challenges and benefits of integrating diverse paradigms. New directions for evaluation (No. 74, pp. 19-32). San Francisco: Jossey-Bass.

Greene, J. C., \& Caracelli, V. J. (2003). Making paradigmatic sense of mixed methods practice. In A. Tashakkori \& C. Teddlie (Eds.), Handbook of mixed methods in 
social and behavioral research (pp. 91-110). Thousand Oaks, CA: Sage.

Hanson, W. E., Creswell, J. W., Plano Clerk, V. L., Petska, K. S., Creswell, J. D. (2004). Mixed Methods Research Design in Counseling Psychology. Journal of Counseling Psychology, 52(2), 224-235; doi 10.1037/0022-0167.52.2.224.

Johnson, R. B. \& Onwuegbuzie, A. J. (2004). Mixed methods research: A research paradigm whose time has come. Educational Researcher, 33(7), 14-26.

Johnson, R. B., Onwuegbuzie, A. J., Turner, L. A. (2007). Toward a definition of mixed methods research. Journal of Mixed Methods Research, 1(2), 112 - 133.

Maxwell, J. A. \& Loomis, D.M. (2003). Mixed methods design: An alternative approach, in A. Tashakkori and C. Teddlie (eds) Handbook of Mixed Methods in Social and Behavioral Research, pp. 209-40. Thousand Oaks, CA: Sage.

Mertens,D.M.(2007). Transformative paradigm: Mixed methodsand socialjustice. Journal of Mixed Methods Research, 1 (3),212 - 225. doi: 10.1177/1558689807302811.

Molina Azorin, J. M. \& Cameron, R. (2010). The application of mixed methods in organizational research: A literature review. The Electronic Journal of Business Research Methods, 8(2), 95 - 105.

Morgan, D. L. (2007). Paradigms lost and pragmatism regained: Methodological implications of combining qualitative and quantitative methods. Journal of Mixed Methods Research, 1(1), 48 -76. Doi: 10.1177/2345678906292462.

Onwuegbuzie, A. J. \& Leech, N. L. (2005). On becoming a pragmatic researcher: The importance of combining quantitative and qualitative research methodologies. International Journal of Social Research Methodology, 8(5), 375-387.

Patton, M. Q. (2002). Qualitative research \& evaluation methods. Thousand Oaks, CA: Sage.

Sandelowski, M. (2000). Focus on research methods: Combining qualitative and quantitative sampling, data collection, and analysis techniques in mixed-method studies. Research in Nursing and Health, 23, 246 - 255. 
Small, M. L. (2011). How to conduct a mixed methods study: Recent trends in a rapidly growing literature. Annual Review Social, 37, 57 - 86.

Teddlie, C. \& Tashakkori, A. (2009). Foundations of mixed methods research. Thousand Oaks: Sage. 